\title{
Kıvırcık ve Yedikule Tipi Marul Çeşitlerinin Kök Gelişimi ve Kök Sistemi Mimarisi Yönünden İncelenmesi
}

\author{
Dilek KANDEMİR ${ }^{1 \mathrm{a} *}$ G. Tuğba ŞAHİN ${ }^{2 \mathrm{~b}}$ Ahmet BALKAYA ${ }^{2 \mathrm{c}}$ Şeyma SARIBAŞ ${ }^{1 \mathrm{~d}}$ \\ ${ }^{1}$ Ondokuz Mayıs Üniversitesi Samsun Meslek Yüksekokulu, Samsun, TÜRKIYY \\ ${ }^{2}$ Ondokuz Mayıs Üniversitesi Ziraat Fakültesi Bahçe Bitkileri Bölümü, Samsun, TÜRKIYE
}

${ }^{a}$ https://orcid.org/0000-0002-3097-3394, ${ }^{b}$ https://orcid.org/0000-0002-3409-4282

chttps://orcid.org/0000-0001-9114-615X, ${ }^{d}$ https://orcid.org/0000-0001-7290-2749

*Sorumlu yazar: mdilek@omu.edu.tr

\section{Ö ZE T}

Kültür bitkilerinde toprak kaynaklı biyotik ve abiyotik stres faktörlerine karşı dayanıklılık düzeyinin, kök sistemi mimarileri ile yakından ilişkili olduğu belirlenmiştir. Bu çalışmada; kıvırcık ve Yedikule tipi marul çeşitlerinin kök sistemi mimarisini oluşturan fenotipik kök özelliklerinin dijital kök görüntüleme sistemlerinden yararlanarak ayrıntılı olarak incelenmesi amaçlanmıştır. Araştırmada, iki farklı marul tipinde farklı firmalardan temin edilen toplam 8 çeşitte (Melina, Funtime, Asturion, Emocion, Mozole, Manto, Likea ve Presidential) kök uzunluğu, ortalama kök çapı, kök yüzey alanı ve kök hacmi özellikleri yönünden kök sistemi mimarileri incelenmiş̧ir. Yedikule marul çeşitleri arasında belirtilen kök parametreleri yönünden istatistiksel olarak önemli düzeyde farklılıkların olduğu, ancak kıvırcık marul çeşitleri arasında ise belirgin bir farklılığın olmadığı tespit edilmiştir. Çalışmada yer alan marul tiplerinde çeşitlere ait kök uzunluklarının oransal çap sınıf değerleri de incelenmiştir. Toplam kök uzunlukları içerisinde, 1 mm'den daha küçük çaplı kök uzunluklarının oranı önemli bir parametredir ve çeşidin saçak kök yapma eğilimini gösterir. Oransal çap sınıf değerleri bakımından kıvırcık marul çeşitleri arasında \%5 düzeyinde ve Yedikule marul çeşitleri arasında \%1 düzeyinde istatistiksel olarak önemli düzeyde farkl1lıkların olduğu belirlenmiștir. Saçak kök yapma eğilimi bakımından kıvırcık marul tipinde \%86.56 değeri ile KM2 çeşidi, Yedikule marul tipinde \%92.66 değeri ile YM4 çeșidi ön plana çıkmıştır. Çalıșmada 60. gün sonunda toplam kök uzunluğunun, kıvırcık marul çeşitlerinde $2705.4 \mathrm{~cm}$ (KM2) ile $3086.4 \mathrm{~cm}$ (KM3) ve Yedikule marul çeşitlerinde ise, $1902.6 \mathrm{~cm}$ (YM2) ile 2838.4 cm (YM4) arasında değişim gösterdiği tespit edilmiştir. Genel olarak, marul bitkisinde kök sistemi mimarisini oluşturan fenotipik kök özelliklerinin kıvırcık marul tipinde daha yüksek değerlere sahip olduğu ve Yedikule marul çeşitlerinin saçak kök yapma eğiliminin daha fazla olduğu saptanmıştır. Kök mimarisine ilişkin bu sonuçların gelecekte bitkilerde su ve gübre kullanımı üzerindeki etkilerine ilişkin çalışmalarda yararlı olacağı düşünülmektedir.

\section{MAKALE B İ L G İS İ}

Araștırma Makalesi

Gelis : 09.09.2021

Kabul: 21.10 .2021

Anahtar kelimeler: Fenotipik kök özellikleri, kök sistemi, marul, WinRhizo programı

\section{Investigation of Root Development and Phenotypic Root Architecture in Curly and Cos Type Lettuce Varieties}

\section{A B S T R A C T}

It has been determined that many tolerance characteristics against soil-borne biotic and abiotic stress factors in cultivated plants are closely related to root system architectures. In this study, it was aimed to examine the phenotypic root characteristics that make up the root system architecture of curly and Cos types of lettuce. In the study, 8 cultivars of two different lettuce types were examined in terms of total root length, average root diameter, root surface area and root volume characteristics. It was determined that there were statistically significant differences only between Cos lettuce varieties. In addition, the proportional diameter class values of the root lengths of the varieties in the lettuce types were also examined. The ratio of root lengths with a diameter of less than $1 \mathrm{~mm}$ in total root lengths is an important parameter and shows the tendency of the variety to form hairy roots. It was determined that there were statistically significant differences at the level of 5\% among the curly lettuce varieties and at the level of $1 \%$ among the cos lettuce varieties. In terms of hairy root tendency, KM2 (86.56\%) in curly lettuce type and YM4 (92.66\%) in Yedikule lettuce type showed higher values. At the end of the 60th day, the total root length was changed between $2705.4 \mathrm{~cm}$ (KM2) and $3086.4 \mathrm{~cm}$ (KM3) in curly lettuce varieties and $1902.6 \mathrm{~cm}$ (YM2) and $2838.4 \mathrm{~cm}$ (YM4) in Yedikule lettuce varieties. In general, it was determined that the phenotypic root characteristics that make up the root system architecture of the lettuce plant have higher values in the curly lettuce type and cos lettuce varieties had a higher hairy root tendency. It is thought that it will be useful to include studies on the effects of root architecture on water and fertilizer use in the future.

\section{A R T I CLE INFO}

Research article

Received: 09.09.2021

Accepted: 21.10 .2021

Keywords:

Phenotypic root traits, root system, lettuce, WinRhizo program

To Cite: $\quad$ Kandemir D, Şahin GT, Balkaya A, Sarıbaş Ş 2021. Kıvırcık ve Yedikule Tipi Marul Çeşitlerinin Kök Gelişimi ve Kök Sistemi Mimarisi Yönünden İncelenmesi. MJAVL Sciences. 11 (2) 120-130 


\section{GİRIș}

Marul (Lactuca sativa L.) dünyada yaprakları tüketilen sebze türleri arasında ön sıralarda yer almaktadır (Eşiyok 2012). Anavatanı Anadolu, Kafkasya, İran ve Türkistan olarak kabul edilmektedir (Balkaya ve Özgen 2019). Yaprak özelliklerine göre kıvırcık yapraklı (L. sativa var. crispa), göbekli (baş) (L. sativa var. capitata) ve Cos marul (L. sativa var. longifolia) olarak gruplandırılmaktadır (Şalk ve ark. 2008). Yedikule marulu, "Roman marulu” ve "Cos marul” olarak da isimlendirilmekte olup, ülkemizde tüketimi en eskiye dayanan gruptur. Cos terimi, Antik Yunan, Romaine terimi ise Roma İmparatorluğu'ndan gelmektedir. Ülkemizde ise Yedikule olarak isimlendirilmiştir. Kıvırcık marul çeşitleri yaprak büyüklükleri, şekil, yaprak rengi ve tekstür özellikleri yönünden çok fazla çeşitlik göstermektedir (Karaağaç ve Balkaya 2019). Marul çeşitleri kısa vejetasyon periyoduna sahip olmaları nedeniyle, Türkiye’nin tüm bölgelerinde yetiştirilebilmekte ve arka arkaya birkaç dikim zamanı planlanarak pazarda devamlılı̆̆ yıl boyu sağlanmaktadır (Kandemir ve Bayındır 2019).

Marul bitkisi toprak isteği bakımından fazla seçici olmayan sebze türüdür. Hafif karakterli topraklardan killi-ağır karakterli topraklara kadar her türlü toprakta kolaylıkla yetiştirilebilir (Murat Doğru ve Çilingir 2019). Marul kısa bir vejetasyon süresine sahip olduğu için farklı toprak yapılarında rahatlıkla büyüme ve gelişme gösterebilmektedir. Ağır topraklarda ise büyüme hızı ve gelişme yavaşlamaktadır. Baş bağlayan çeşitlerde ise ortalama baş ağırlığı belirgin olarak azalış göstermektedir. Ayrıca, marul bitkisi, toprak tuzluluğuna karşı hassas bir sebze türüdür (Ayers ve Westcot 1989; Güvenç 2016). Marul yetiştiriciliğinde pH değeri 6.0-7.0 arasında olmalı, 6.0'nın altında olduğu durumlarda toprağa kireç ilavesi yapılmalıdır (Denli 2015). Ayrıca ekim nöbeti uygulanırken marul yetiştiriciliğinden sonra tekrar aynı yerde marul yetiştiriciliği yapılmamalıdır. $\mathrm{Bu}$ durumda, marul yetiştirmeden önce baklagillerin yetiştirilmesi gereklidir. Böylece marul yetiştiriciliğinde verim değerlerinin ve ürün kalitesinin artırılması mümkün olmaktadır (Açıkgöz 2001).

Son yıllarda bitki kök gelişimi ve mimarisi, iklim değişimi ve artan kuraklık baskısı nedeniyle artan bir ilgi ve önem dönemi yaşamaktadır. Kök gelişiminin aynı toprak üstü organların gelişiminde olduğu gibi, 3 boyutlu ve kompleks bir gelişim sistemi olduğu bilinmektedir (Bektaş, 2021). Marulun kök yapısı, büyüme döneminde başlangıçta oldukça zayıftır. Kökler daha çok toprak yüzeyinde yoğunlaşmıştır. Marul bitkisi olgunlaşma ile birlikte etrafı saçak köklerle çevrili olan, kuvvetli ve derinlere inen güçlü kazık kök yapısına sahip olur (Sarıbaş ve Şen, 2019). Marul bitkisinde saçak kökler genelde $20-30 \mathrm{~cm}$ derinliğe yüzeysel olarak yayılmışlardır. Ancak uygun toprak koşullarında ve çiçeklenme döneminde kazık kök ise yaklaşık $100 \mathrm{~cm}$ derinlere kadar inebilmektedir (Günay 2005; Özgür 2016). Toprak altında bulunan kök kısmının incelenmesi ve fenotipik yapının belirlenmesi oldukça zordur. Ancak son yıllarda, gelişen dijital görüntüleme sistemlerinin kullanılması ile bitkilerin kök yapıları üzerinde detaylı incelemeler yapılabilmektedir (Paez-Garcia ve ark. 2015; Sarıbaş ve ark. 2019; Karaağaç ve ark. 2020; Kanal ve ark. 2021). Kök sisteminin mimari yapısı çevresel ve hormonal uyartılarla şekillenmektedir (Lopez-Bucio ve ark. 2003). Marul bitkisinde de kök yapılarının ayrıntılı olarak incelenmesine yönelik olarak yurt dışında bazı çalışmalar yapılmıştır (Jackson 1995; Johnson ve ark. 2000; Murakami ve ark. 2002; Li ve ark. 2018). Bu çalışmalarda kültüre alınan marul çeşitlerinin ve yabani marul türlerinin kök yapıları karşılaştırılmış (Jackson 1995), farklı gübre ve malç uygulamalarının marul kök yapısı üzerine etkileri incelenmiş (Murakami ve ark. 2002) ve marul yetiştiriciliğinde değişik yetiştirme ortamlarının (su kültürü, katı ortam kültürü ve aeroponik kültür) marul bitkisinde kök yapısı ve bitki büyümesi üzerine olan etkileri belirlenmiştir ( $\mathrm{Li}$ ve ark. 2018). Ülkemizde ise marul bitkisinde fenotipik kök mimarisini ortaya koyan ayrıntılı bir çalışma yok denilecek kadar azdır. Bu araştırma ile dijital kök görüntüleme sistemlerinden yararlanarak kıvırcık ve Yedikule tipi marul çeşitlerinin kök gelişimlerinin belirlenmesi ve kök sistemi mimarisini oluşturan fenotipik kök özelliklerinin detaylı olarak incelenmesi amaçlanmıştır.

\section{MATERYAL VE METOT}

Araştırma, 2020 yılı sonbahar döneminde Ondokuz Mayıs Üniversitesi Ziraat Fakültesi sera ünitesinde bulunan sebze çoğaltma serasında ve Bahçe Bitkileri Bölümü Fizyoloji Laboratuvarında yürütülmüştür. Çalışmada farklı firmalardan temin edilen toplam 8 marul çeşidi kullanılmıştır. Bunların 4 adeti kıvırcık tipte marul çeşitlerinden (Melina, Funtime, Asturion ve Emocion) ve diğer 4 adeti ise Yedikule tipi marul çeşitlerinden (Mozole, Manto, Likea ve Presidential) oluşmaktadır. Marul çeşitleri arasında fide kalitesi yönünden bir örnekliğin sağlanması için marul fideleri, Bakır Fide işletmesinde tarafımızdan kontrollü olarak aynı zamanda yetiştirilmiştir. Denemede dört gerçek yapraklı döneme ulaşan marul fideleri; içerisinde torf:perlit (2:1 oranında, v:v) karışımının bulunduğu 3 litrelik $(19$ x $17.5 \mathrm{~cm})$ plastik saksılara, 16.10.2020 tarihinde tesadüf parselleri deneme desenine uygun olarak üç tekerrürlü ve her tekerrürde 18 bitki olacak şekilde aynı zamanda dikilmiştir. Marul fideleri ısıtmasız serada 60 gün boyunca yetiştirilmiş ve bu süre boyunca sıcaklık değerleri datalogger (sıcaklık kaydedici) ile ölçülmüştür (Şekil 1). Marul bitkilerinin ihtiyaç duyduğu besin elementleri yetiştiricilik dönemi boyunca düzenli olarak Horuz (2019)'a göre verilmiştir. 


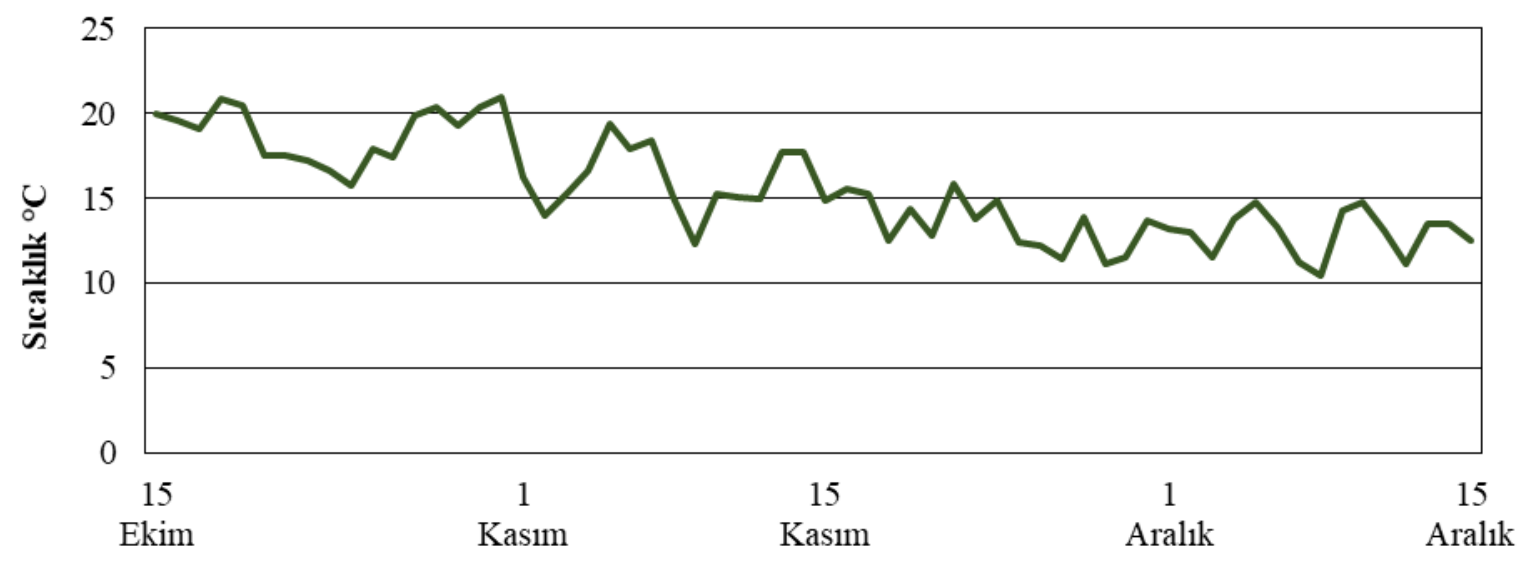

Şekil 1. Dikimden itibaren serada günlük ortalama sıcaklık değerlerinin değişimi

Marul bitkilerinde kök mimarisinin incelenmesi, kök gelişimi ve köklenme potansiyelinin belirlenebilmesi amaciyla WinRhizo kök analiz programı (ver. 2013, Regent Instruments, QC, Canada) kullanılmıştır (Sarıbaş ve ark. 2019; Kanal ve ark. 2021). Çalışmada, dikim aşamasına gelen marul fidelerinde başlangıç kök yapıları incelenmiştir. Saksılara fide dikiminden itibaren 10'ar gün aralıklarla 60. gün sonuna kadar toplam 7 defa kantitatif kök analizleri yapılmıştır. Bu amaçla, marul bitkilerinin kökleri dikkatli bir şekilde yıkanmış ve kökler zarar görmeyecek şekilde kağıt havlu ile kurutulmuştur. Daha sonra kökler, A3 boyutundaki asetat üzerine yerleştirilmiş ve cihaz tarafından detaylı olarak algılanacak şekilde köklerde dikkatli bir şekilde ayırma işlemi gerçekleştirilmiştir (Şekil 2). Tarama (scanning) işlemine hazır hale getirilmiş olan kökler, cihazın tarayıcı (scanner) (Epson Expression 10 000XL, Epson America Inc., Long Beach, CA, USA) kısmına konularak 400 dpi çözünürlükte üç boyutlu olarak bilgisayar ortamına aktarılmıştır.

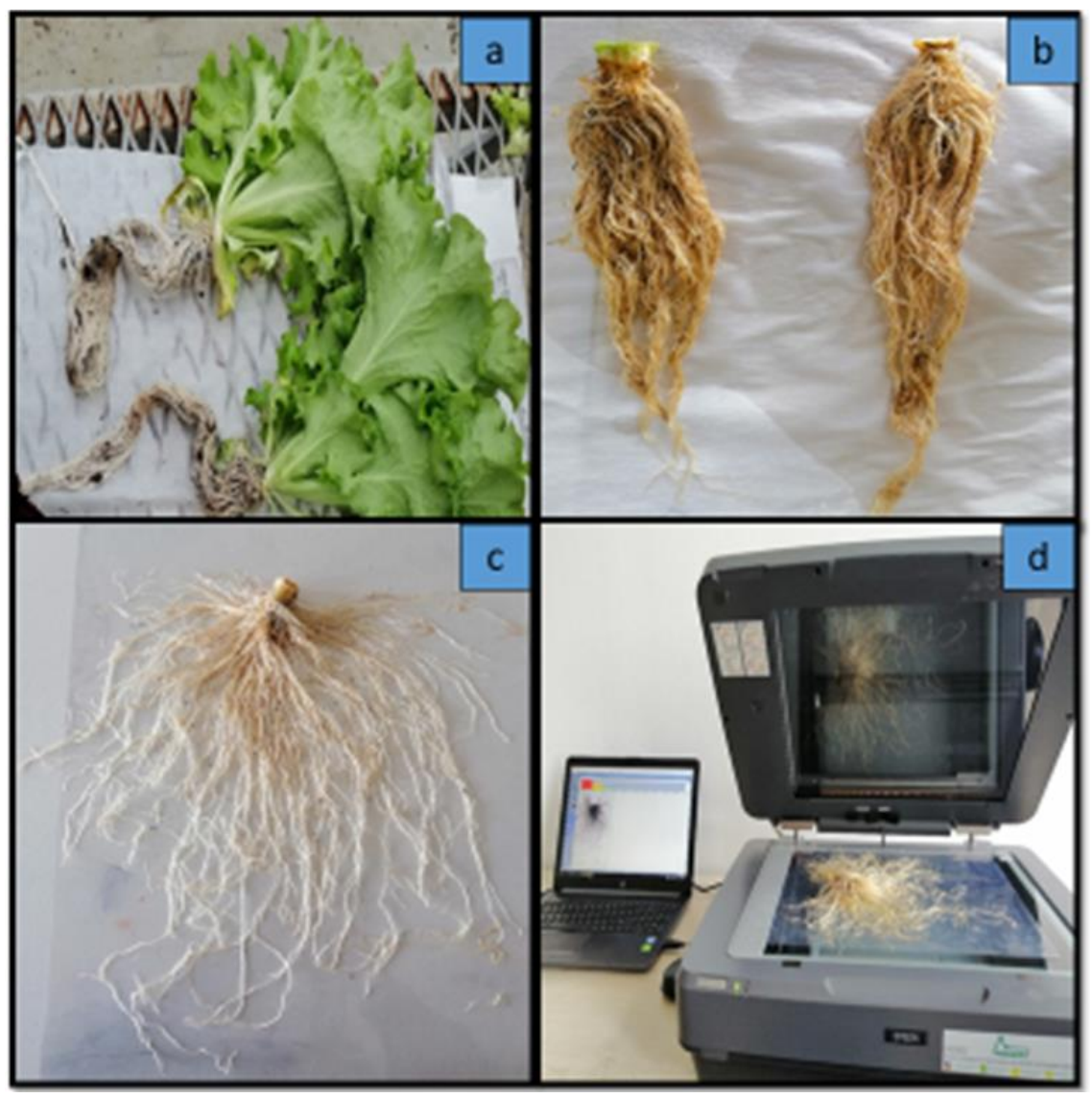

Şekil 2. Marul bitkisinde köklerin analize hazırlanması aşamaları (a. Kantitatif hasat b. Yıkanmış kökler c. Köklerin ayırılması d. Köklerin taranması) 
Marul çeşitlerinde aşağıda belirtilen fenotipik kök özellikleri yönünden incelemeler yapılmıştır (Johnson ve ark. 2000; Murakami ve ark. 2002; Li ve ark. 2018).

a) Toplam kök uzunluğu (cm): Tüm marul çeşitlerinde tüm çap sınıflarındaki köklerin toplam uzunlukları belirlenmiş̧ir.

b) Ortalama kök çapı (mm): Marul çeşitlerinde tüm kök uzantıları WinRhizo programı yardımıyla bireysel olarak incelenerek ortalama kök çapları hesaplanmıştır.

c) Kök yüzey alanı $\left(\mathbf{c m}^{2}\right)$ : Tüm köklerin dış çeperlerinin yüzey alanı, kök yüzey alanı (izdüşümü alanları) olarak hesaplanmıştır.

d) Toplam kök hacmi $\left(\mathbf{c m}^{3}\right)$ : Kantitatif olarak analiz edilen marul çeşitlerine ait köklerde, WinRhizo programı ile net kök hacmi değerleri ölçülmüştür.

e) Kök uzunluklarının oransal çap sınıf değerleri (\%): Marul bitkilerinin toplam kök uzunluğu, sahip oldukları çapa göre gruplandırılarak üç sınıfta incelenmiştir. Birinci sınıfta (Sınıf 1) çapı 1.0 mm'den küçük olan kök uzunluk oranı $(C ̧<1 \mathrm{~mm}$ ), ikinci sınıfta (Sınıf 2) çapı 1.0 ile $2.0 \mathrm{~mm}$ arasındaki kök uzunluk oranı $(1<C ̧<2 \mathrm{~mm})$ ve üçüncü sınıfta (Sınıf 3) $2.0 \mathrm{~mm}$ 'den büyük kök çaplarının uzunluk oranı $(C ̧>2 \mathrm{~mm})$ değerlendirilmiş̧ir. Ayrıca marul çeşitlerinde kök gelişim düzeylerinin ayrıntılı olarak ortaya konulabilmesi için yukarıda belirtilen kök parametreleri yönünden 10'ar gün aralıklarla yapılan kantitatif ölçüm sonuçlarına göre ortaya çıkan değişimler de tespit edilmiştir.

Yapılan çalışma sonucunda elde edilen tüm verilere, varyans analizi (ANOVA) yapılmış ve ardından istatistiksel olarak önemli bulunan parametreler Tukey testine göre gruplandırılmıştır.

\section{BULGULAR}

Çalışmada, iki farklı marul tipinde toplam 8 çeşitte kök sistemi mimarisini oluşturan fenotipik kök özellikleri (kök uzunluğu, ortalama kök çapı, kök yüzey alanı ve kök hacmi) yönünden Yedikule marul çeşitleri arasında istatistiksel olarak önemli düzeyde farklılıkların olduğu, ancak kıvırcık marul çeşitleri arasında ise farklılık olmadığı tespit edilmiştir. Dikimden itibaren 60. gün sonunda yapılan kök tarama analizi sonuçlarına göre toplam kök uzunluğu değerleri, kıvırcık marul çeşitlerinde $2705.4-3086.4 \mathrm{~cm}$ ve Yedikule marul çeşitlerinde ise $1902.6-2838.4 \mathrm{~cm}$ arasında değişim göstermiştir (Şekil 3). Yapılan varyans analizi sonucunda ortalama kök çapı değerleri bakımından Yedikule marul çeşitlerinin istatistiksel olarak önemli düzeyde farklılık $(\mathrm{p}<0.01)$ gösterdikleri saptanmıştır. YM4 kodlu Yedikule marul çeşidinde en yüksek toplam kök uzunluğu değeri $(2838.4 \mathrm{~cm})$ belirlenmiştir. En düşük toplam kök uzunluğu ise YM2 çeşidinde $1902.6 \mathrm{~cm}$ olarak ölçülmüsşür. YM4 çeşidinin toplam kök uzunluğu değerinin YM2 çeşidinden \% 49.19 oranında daha fazla olduğu hesaplanmıştır. Ayrıca araştırma sonucunda kıvırcık marullarda toplam kök uzunluğu değerinin $(2876.7 \mathrm{~cm})$, Yedikule tipi marul çeşitlerinden $(2434 \mathrm{~cm}) \% 18.19$ oranında daha yüksek olduğu da belirlenmiştir.

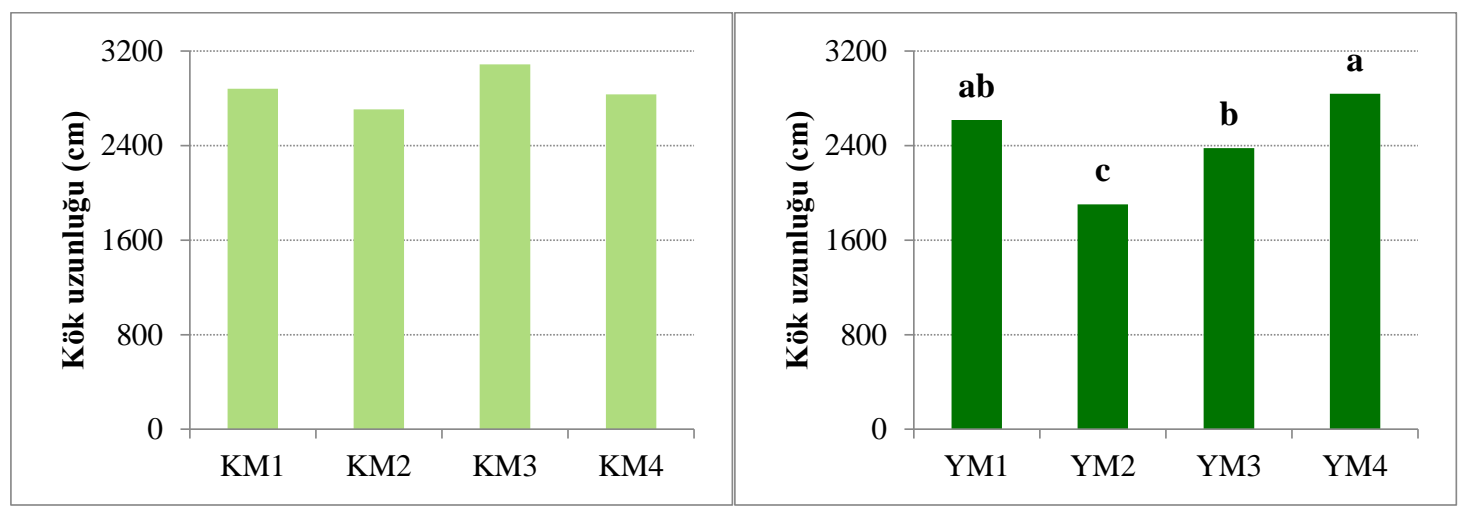

Şekil 3. Kıvırcık ve Yedikule tipi marul çeşitlerinde dikimden itibaren 60. günde sonra belirlenen kök uzunluğu (cm) değerleri

Araştırma sonucunda 10 'ar günlük aralıklarla yapılan kantitatif kök analizleri sonucunda; genel olarak marul tipi, çeşit özelliği ve sıcaklık nem gibi bitki ekolojisine bağlı olarak incelenen kök özelliklerinde bazı dönemlerde daha hızlı bir büyüme belirlenmiş, bazı dönemlerde ise daha yavaş bir büyümenin olduğu tespit edilmiştir. Her iki marul tipinde de toplam kök uzunluğu artış miktarı dikimden 20. güne kadar oldukça yavaş bir seyir izlemiş, 20. gün ile 40. gün arasında ise hızlı bir büyümenin olduğu saptanmıştır (Şekil 4). Kıvırcık marul çeşitlerinde, 20. güne göre 40. gündeki 
toplam kök uzunluğu artış miktarı en yüksek KM2 (9.46 katı) çeşidinde, en düşük ise KM4 çeşidinde (7.47 katı) kaydedilmiştir. Yedikule tipi marul çeşitlerinde ise 20. güne göre 40. gün sonunda toplam kök uzunluğu artış miktarı en yüksek YM1 çeşidinde (7.38 katı) ve YM3 çeşidinde ise en düşük (4.26 katı) olarak belirlenmiştir. Araştırmada 60. gün sonunda 40. güne göre en yüksek kök uzunluğu artış oranı \% 25.68 değeri ile KM2 çeşidinde ve \%28.17 değeri ile YM3 çeşitlerinde gerçekleşmiştir.

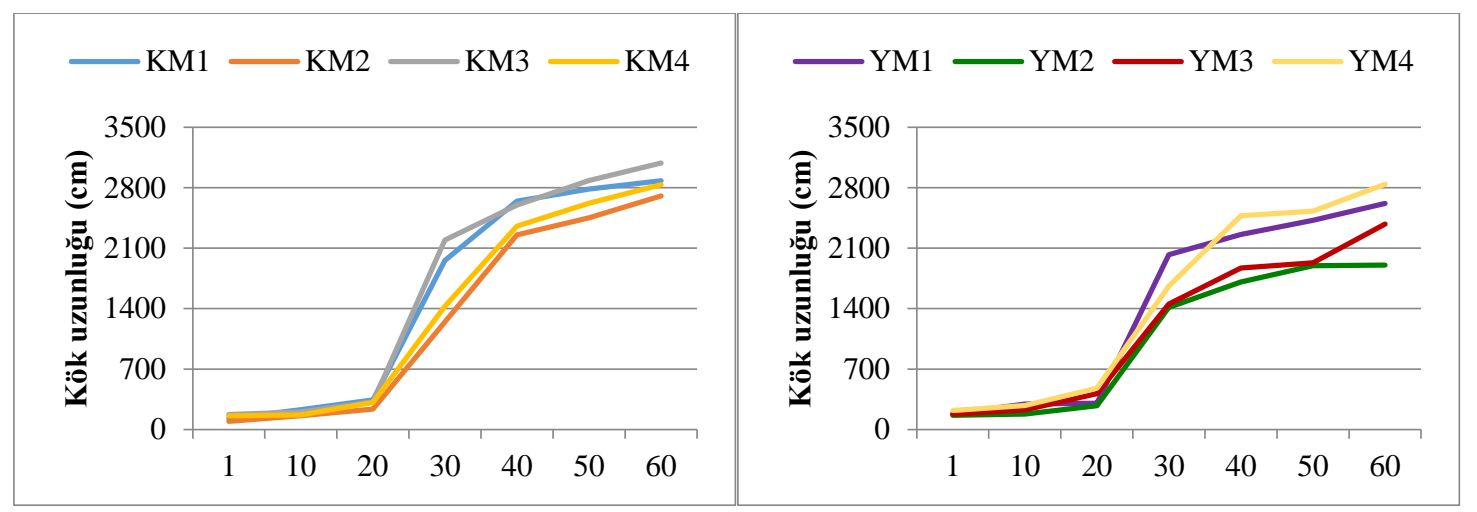

Şekil 4. Kıvırcık ve Yedikule marul çeşitlerinde dikimden itibaren 10 gün aralıklarla ölçülen kök uzunluğu (cm) değerleri

Marul çeşitlerinde 60. gün sonunda, ortalama kök çapının 0.65-0.83 mm arasında değişim gösterdiği saptanmıştır (Şekil 5). Marul ürün tiplerini ayrı ayrı değerlendirdiğimizde, kıvırcık marulda ortalama kök çapı değerleri bakımından çeşitler arasında istatistiksel olarak önemli düzeyde bir farklılık olmadı̆̆ı, Yedikule çeşitleri arasında ise önemli düzeyde $(\mathrm{p}<0.05)$ farklılık olduğu saptanmıştır. Yedikule marul çeşitlerinde en yüksek ortalama kök çapı değeri 0.76 mm ile YM1 çeşidinde ölçülmüştür. Diğer üç çeşidin ortalama kök çapı değerleri ise aynı istatistiki grupta yer almıştır. Araştırma sonucunda kıvırcık marul çeşitlerinin ortalama kök çapı $(0.79 \mathrm{~mm})$ değerlerinin, Yedikule marul çeşitlerinden $(0.70 \mathrm{~mm})$ daha yüksek olduğu bulunmuştur.

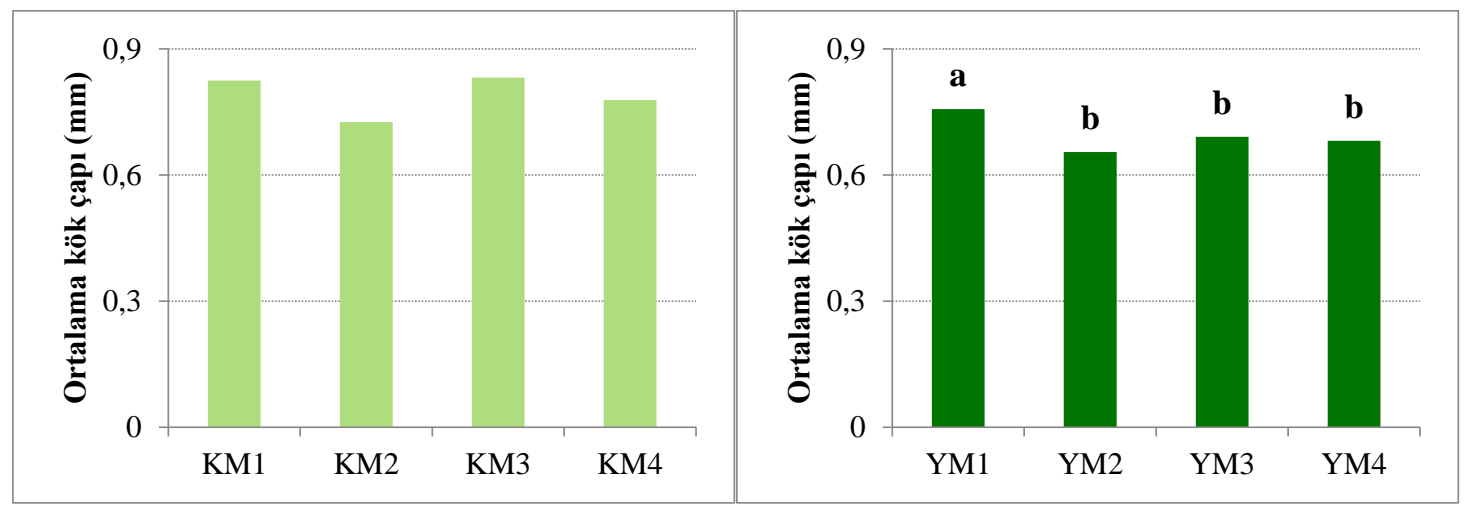

Şekil 5. Kıvırcık ve Yedikule tipi marul çeşitlerinde dikimden itibaren 60. günde belirlenen ortalama kök çapı (mm) değerleri

Marul çeşitlerinde 60 gün süresince kök çapı yönünden belirlenen değerler, Şekil 6’da verilmiştir. Her iki marul tipinde de ilk 20 günde ortalama kök çapında hafif bir artış kaydedilmiş, ancak 20. ile 30. günler arasında düşüş̧ gerçekleşmiştir. Bu düşüşün kıvırcık marul çeşitlerinde \%24.49 oranında ve Yedikule marul çeşitlerinde ise \%26.77 oranında olduğu kaydedilmiştir. Çeşitler bazında en fazla düşüş KM1 (\%27.83) ve YM3 (\%28.35) çeşitlerinde tespit edilmiştir. 30. günden sonra ortalama kök çapı her iki marul çeşitlerinde de artış göstermiş ve kıvırcık marul çeşitlerindeki artışın daha fazla olduğu belirlenmiştir. 


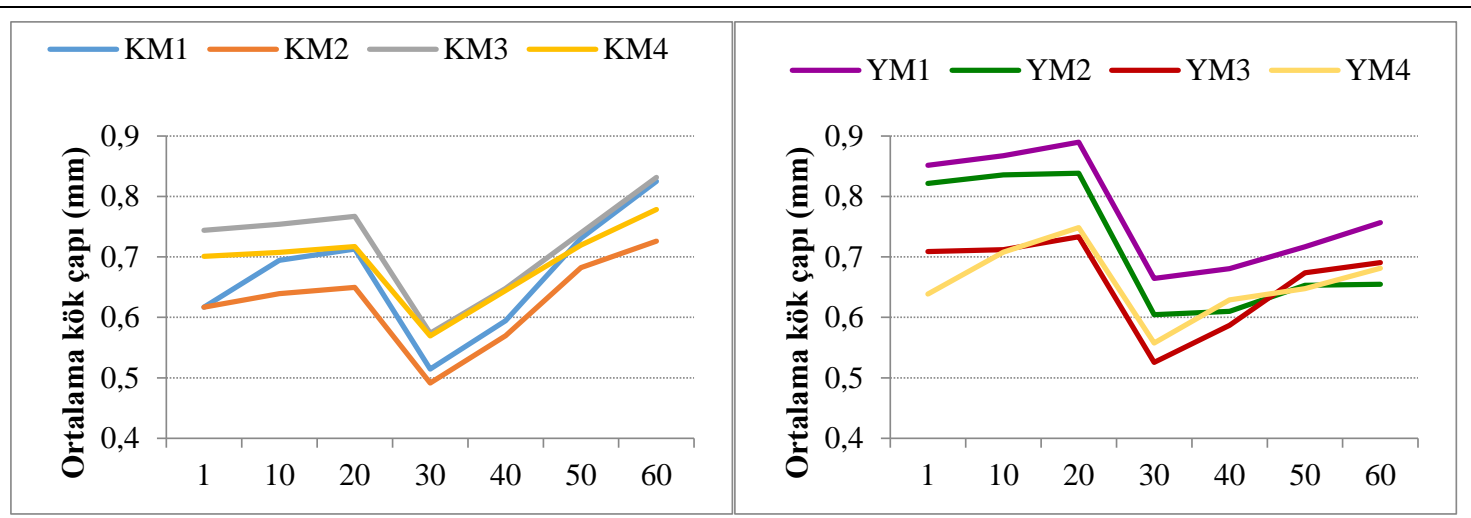

Şekil 6. Kıvırcık ve Yedikule marul çeşitlerinde dikimden itibaren 10 gün aralıklarla ölçülen ortalama kök çapı (mm) değerleri

Tüm marul çeşitlerinde kök yüzey alanı değerleri, $358.54 \mathrm{~cm}^{2}$ ile $678.05 \mathrm{~cm}^{2}$ arasında değişim göstermiştir. İncelenen iki marul tipinden Yedikule marul çeşitleri arasında kök yüzey alanı yönünden farklılıkların çok önemli $(p<0.01)$ düzeyde olduğu tespit edilmiştir. Yedikule marul tipinde en yüksek kök yüzey alanı YM4 çeşidinde $642.49 \mathrm{~cm}^{2}$ olarak ölçülmüştür. En düşük değer ise YM2 çeşidinde $\left(358.54 \mathrm{~cm}^{2}\right)$ tespit edilmiştir (Şekil 7). Marul tipleri bazında kök yüzey alanı değerleri karşılaştırıldığında; kıvırcık marul tipinde olan çeşitlerin daha yüksek değer aldığı belirlenmiştir.

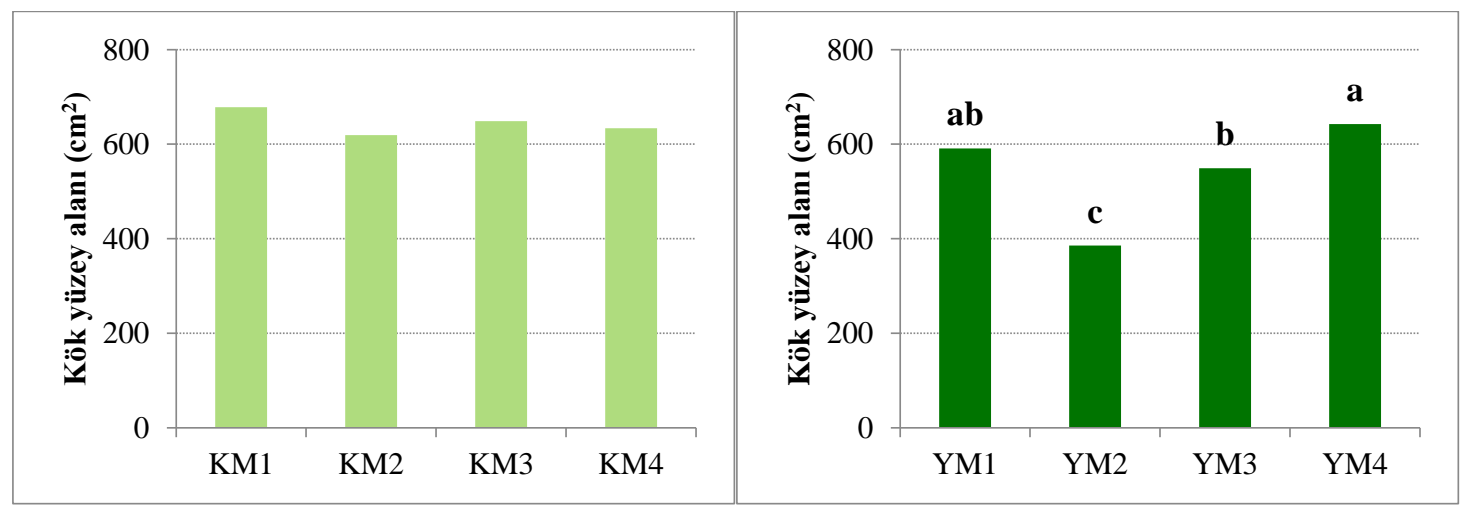

Şekil 7. Kıvırcık ve Yedikule tipi marul çeşitlerinde dikimden itibaren 60. günde belirlenen kök yüzey alanı $\left(\mathrm{cm}^{2}\right)$ değerleri

Kıvırcık ve Yedikule marul ürün segment grubunda yer alan çeşitlerde 10'ar günlük aralıklarla yapılan kök analizleri sonucunda kök yüzey alanı değerleri yönünden değişimleri Şekil 8'de sunulmuştur. Kök yüzey alanı değerleri, tüm marul çeşitlerinde genel olarak 20. güne kadar hafif bir artış izlemiş, 20. günden sonra ise hızlı bir yükseliş göstermiştir. Kıvırcık marul çeşitlerinde dikimden itibaren 20. gün sonunda belirlenen kök yüzey alanı değerlerine göre 60. gündeki kök yüzey alanı değerlerinin; KÇ2 çeşidinde 11.97 kat, KÇ3'de 11.51 kat, KÇ4'de 9.29 kat ve KÇ1 çeşidinde ise 8.44 kat arttı̆̆ tespit edilmiştir. Bu değer, Yedikule marul çeşitlerinde 6.22 kat (YÇ1), 6.18 kat (YÇ4), 5.32 kat (YÇ2) ve 5.28 kat (YÇ3) olarak hesaplanmıştır. Sonuç olarak kıvırcık marul çeşitlerinde kök yüzey alanı artış miktarının, Yedikule marul çeşitlerinden daha fazla olduğu belirlenmiştir. 


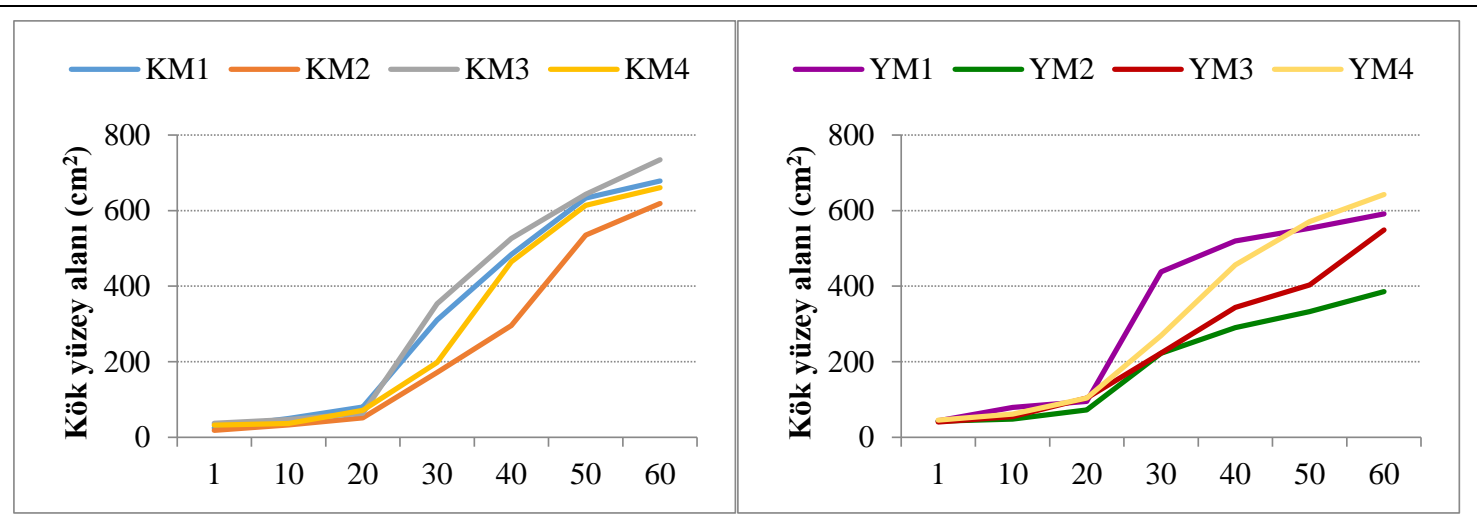

Şekil 8. Kıvırcık ve Yedikule marul çeşitlerinde dikimden itibaren 10 gün aralıklarla ölçülen kök yüzey alanı $\left(\mathrm{cm}^{2}\right)$ değerleri

Çalışmada, Yedikule marul çeşitlerinin kök hacmi değerlerinin istatistiksel olarak çok önemli düzeyde farklılıklar gösterdiği $(\mathrm{p}<0.01)$ tespit edilmiştir (Şekil 9). YM1 çeşidinde $9.86 \mathrm{~cm}^{3}$ değeri ile en yüksek kök hacmi değeri saptanmıştır. Bu çeşidi $9.03 \mathrm{~cm}^{3}$ ile YM4 ve $8.45 \mathrm{~cm}^{3}$ değeri ile YM3 çeşitleri izlemiştir. Bu üç çeşit istatistiksel olarak aynı grup içerisinde yer almıştır. YM2, $6.02 \mathrm{~cm}^{3}$ kök hacmi değeri ile en düşük kök hacmi değeri gösteren çeşit olmuştur. Araştırma sonucunda, kıvırcık marul çeşitlerinin ortalama kök hacmi değerinin $\left(13.50 \mathrm{~cm}^{3}\right)$, Yedikule marul çeşitlerinin ortalama kök hacmi değerinden $\left(8.34 \mathrm{~cm}^{3}\right)$, yaklaşı \%61.87 oranında daha fazla olduğu hesaplanmıştır.

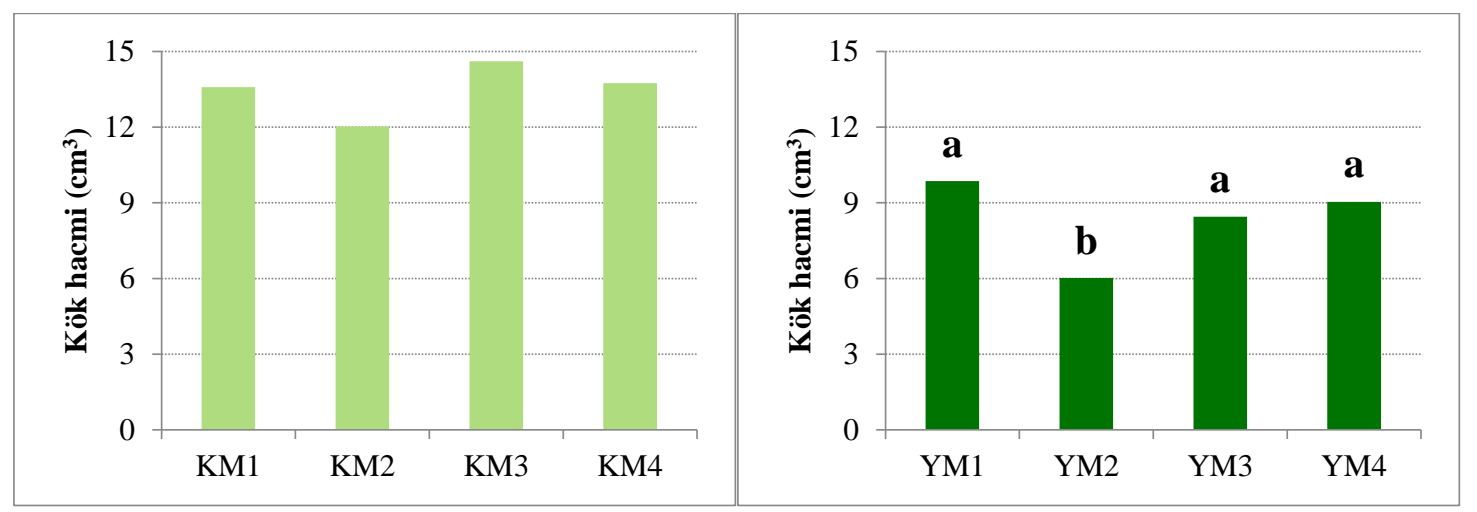

Şekil 9. Kıvırcık ve Yedikule tipi marul çeşitlerinde dikimden itibaren 60. günde belirlenen kök hacmi $\left(\mathrm{cm}^{3}\right)$ değerleri

Kıvırcık marul çeşitlerinde 20. gün sonunda dikim gününe göre kök hacmi artış miktarı, kıvırcık marullarda 2.59 kat ve Yedikule marullarında ise 2.29 kat düzeyinde olmuştur. Ayrıca 20. gün ile 40. günler arasında $5.82 \mathrm{~kat}(\mathrm{KM})$ ile 3.36 kat (YM) ve 40. ile 60. günler arasında ise 2.04 kat (KM) ile 1.32 kat (YM) artış olduğu tespit edilmiştir. Her iki marul tipinde de en hızlı kök hacmi artış miktarı 20. ile 40. günler arasında gerçekleşmiştir.

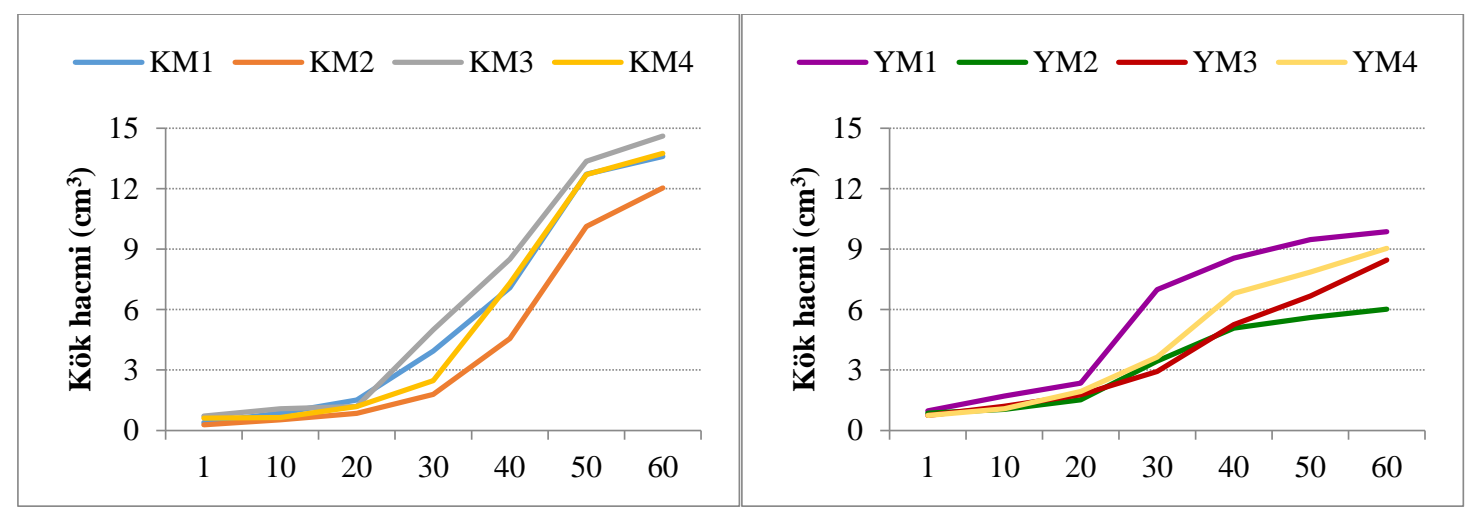

Şekil 10. Kıvırcık ve Yedikule marul çeşitlerinde dikimden itibaren 10 gün aralıklarla ölçülen kök hacmi $\left(\mathrm{cm}^{3}\right)$ değerleri 
Çalışmada yer alan marul tiplerinde çeşitlere ait kök uzunlukları oransal çap sınıf değerleri (\%) yönünden incelendiğinde, kıvırcık marul çeşitleri arasında $\% 5$ düzeyinde ve Yedikule marul çeşitleri arasında ise \%1 düzeyinde istatistiksel olarak farklılıklar olduğu belirlenmiştir (Tablo 1).

Marul tiplerinin köklerinin; toplam kök uzunlukları içerisinde, 1 mm'den daha küçük çaplı kök uzunluklarının oranı önemli bir parametredir ve çeşidin saçak kök yapma eğilimini gösterir. Çapı $1 \mathrm{~mm}$ 'den az olan kök uzunluğu oranı değerleri (Sınıf 1) \%81.4 ile \%92.66 arasında dağılım göstermiştir. Saçak kök yapma eğilimi bakımından kıvırcık marul tipinde \%86.56 değeri ile KM2 çeşidi, Yedikule marul tipinde \%92.66 değeri ile YM4 çeşidi ön plana çıkmıştır. En düşük saçak kök yapma eğilimi ise kıvırcık marul tipinde KM1 çeşidinde (\%81.40) ve Yedikule marul tipinde ise YM1 (\%87.68) çeşidinde tespit edilmiştir (Tablo 1). Araştırma sonunda, marul tiplerinin saçak kök yapma eğilimleri genel olarak incelendiğinde, Yedikule marul çeşitlerinin saçak kök yapma eğiliminin daha fazla olduğu belirlenmiştir.

Araştırmada, çapı 1-2 mm aralığında olan kök uzunluklarının oranı (Sınıf 2) kıvırcık marul çeşitlerinde \%9.88-13.08 ve Yedikule marul çeşitlerinde ise \%5.53-9.08 arasında dağılım göstermiştir. Bu özellik bakımından KM1 (\%13.08) ve KM3 (\%12.31) kıvırcık marul çeşitleri ile YM1 (\%9.08) Yedikule marul çeşidi en yüksek değerleri göstermiştir (Çizelge 1).

Çapı 2 mm'den fazla olan kök uzunluklarının oranı (Sınıf 3) \%1.80 ile \%5.51 arasında değişim göstermiştir. Kıvırcık marul ve Yedikule marul tiplerinde en yüksek Sınıf 3 değeri, saçak kök yapma eğilimi en düşük olan (Sınıf 1) KM1 (\%5.51) ve YM1 (3.22) çeşitlerinde kaydedilmiştir.

Çizelge 1. Klvırcık ve Yedikule marul çeşitlerinde kök uzunluklarının oransal çap sınıf değerleri (\%)*

\begin{tabular}{|c|c|c|c|c|c|c|c|}
\hline Çeşit & $\begin{array}{c}\text { Sinıf } 1 \\
(C ̧<1 \mathrm{~mm})\end{array}$ & $\begin{array}{c}\text { Sinıf } 2 \\
(1<C ̧<2 \mathrm{~mm})\end{array}$ & $\begin{array}{c}\text { Sinıf } 3 \\
(C ̧>2 \mathrm{~mm})\end{array}$ & Çeşit & $\begin{array}{c}\text { Sinıf } 1 \\
(C ̧<1 \mathrm{~mm})\end{array}$ & $\begin{array}{c}\text { Sinıf } 2 \\
(1<C ̧<2 \mathrm{~mm})\end{array}$ & $\begin{array}{c}\text { Sinıf } 3 \\
(C ̧>2 \mathrm{~mm})\end{array}$ \\
\hline KM1 & $81.40 b^{*}$ & $13.08 \mathrm{a}$ & $5.51 \mathrm{a}$ & YM1 & $87.68 \mathrm{c}$ & $9.08 \mathrm{a}$ & $3.22 \mathrm{a}$ \\
\hline KM2 & $86.56 \mathrm{a}$ & $9.88 \mathrm{~b}$ & $3.54 \mathrm{~b}$ & YM2 & $90.33 \mathrm{~b}$ & $5.53 \mathrm{c}$ & $1.80 \mathrm{c}$ \\
\hline KM3 & $83.99 \mathrm{ab}$ & $12.31 \mathrm{a}$ & $3.68 \mathrm{~b}$ & YM3 & $91.14 \mathrm{~b}$ & $6.79 \mathrm{~b}$ & $2.05 \mathrm{c}$ \\
\hline KM4 & $83.98 \mathrm{ab}$ & $11.03 \mathrm{ab}$ & $4.97 \mathrm{ab}$ & YM4 & $92.66 \mathrm{a}$ & $7.32 \mathrm{~b}$ & $2.34 \mathrm{~b}$ \\
\hline $\mathrm{P}$ & $\leq 0.05$ & $\leq 0.05$ & $\leq 0.05$ & $\mathrm{P}$ & $\leq 0.01$ & $\leq 0.01$ & $\leq 0.01$ \\
\hline
\end{tabular}

*Aynı harfle gösterilen ortalamalar arasındaki farklar önemli değildir.

\section{TARTIŞMA}

Tüm sebze türlerinde olduğu gibi marul yetiştiriciliğinde de yüksek verim ekonomik açıdan en önemli özelliktir. Bitkileri yetiştiği ortama bağlayan kök sistemi, su ve besin alımı gibi çeşitli fizyolojik işlevleri önemli ölçüde etkileyerek, özellikle stres koşulları altında bitki büyümesi ve verimliliği üzerinde önemli bir rol oynamaktadır (Bertucci ve ark. 2018; Sarıbaş ve ark. 2019). Marulda kök sistemi mimarisinin incelendiği bu çalışmada, dikimden itibaren 60. günde kaydedilen toplam kök uzunluğu, ortalama kök çapı, kök yüzey alanı ve kök hacmi gibi fenotipik kök özellikleri bakımından Yedikule marul çeşitleri arasında istatiksel olarak önemli düzeyde farklılıkların olduğu saptanmıştır. Ancak kıvırcık marul çeşitleri arasında ise belirgin bir farklılık tespit edilmemiştir. Johnson ve ark. (2000), marul tiplerinin hem sürgün hem de kök özellikleri bakımından yüksek oranda büyük farklılıklar gösterdiğini bildirmişlerdir. Araştırmada, kıvırcık ve Yedikule marul çeşitlerinde toplam kök uzunluğu değeri 1902.6-2881.4 cm arasında değişmiştir. En yüksek toplam kök uzunluğu $2838.4 \mathrm{~cm}$ değeri ile YM4 çeşidinde belirlenmiştir. En düşük ise $1902.6 \mathrm{~cm}$ değeri ile YM2 çeşidinde kaydedilmiştir. YM4 çeşidinin toplam kök uzunluğu değerinin YM2 çeşidinden \% 49.19 oranında daha fazla olduğu hesaplanmıştır. Li ve ark. (2018) 45 gün boyunca yetiştirdikleri iki farklı marul genotipinde toplam kök uzunluğu değerlerinin $581 \mathrm{~cm}$ ile $3043 \mathrm{~cm}$ arasında değiştiğini bildirmişlerdir. Özellikle düşük fosforlu veya kurak koşullar gibi stres koşullarında, bitkilerde iyi bir şekilde su ve iyon alımı için köklerin toprağın derinliklerine kadar büyümesi ve daha yüksek toplam kök uzunluğuna sahip olması istenmektedir (Krasilnikoff ve ark. 2003; Lambers ve ark. 2006; Comas ve ark. 2013). Ayrıca daha uzun bir kök sistemi, nitrat emilimi açısından da önemli bir özelliktir (Koevoets ve ark. 2016). Marul bitkisinde kök mimarisindeki değişiklikler yoluyla artan kök uzunluğunun, toprak kaynaklarının daha derin bir şekilde geri kazanılmasını teşvik ettiği ve aynı kök biyokütlesine sahip iki bitkiden daha uzun bir kök sistemine sahip olan bitkinin daha derin toprak bölgelerine kolaylıkla erişebildiği ve böylece daha bol su ve besin tedarik ettiği Johnson ve ark. (2000) tarafından bildirilmişsir.

Marul tiplerinde ortalama kök çapı değerleri, 0.65-0.83 mm arasında dağılış göstermiştir. Araştırma sonuçlarına göre ortalama kök çapı değeri bakımından Yedikule marul çeşitleri arasında istatistiksel olarak önemli düzeyde $(\mathrm{p}<0.05)$ farklılık olduğu, ancak Kıvırcık marul çeşitleri arasında belirgin bir farklılığın olmadığı saptanmıştır. Çalışmada en yüksek ortalama kök çapı YM1 $(0.19 \mathrm{~mm})$ çeşidinde belirlenmiştir. Diğer üç çeşit ise aynı istatistiki grupta yer 
almıştır. Li ve ark (2018), iki farklı marul tipinde dikiminden 45 gün sonra, ortalama kök çapının 0.48-0.55 mm arasında değiştiğini ve marul tipinin kök çapı üzerine etkisinin olmadığını kaydetmişlerdir. Araştırma sonuçları, belirtilen literatür ile genel olarak uyumluluk göstermiştir. Farklılık, çeşit etkisinden kaynaklanabilir. Eissenstat (1992), ortalama kök çapı değerinin, saçak kök eğiliminin önemli bir göstergesi olduğunu ve kök çapının, kökün emme kabiliyetini olumlu yönde etkilediğini bildirmiştir. Her iki marul tipinde de ilk 20 günde ortalama kök çapında hafif bir artış kaydedilmiş, ancak 20. ile 30. günler arasında düşüş gerçekleşmiştir. 20. ile 30. günler arasındaki dönemde gerçekleşen kök uzunluğundaki hızlı artış kök çaplarında azalışa neden olmuştur. Lovelli ve ark. (2012) kök uzunluk oranının artmasıyla kök çapının azaldığını ve bunun da su kullanım verimliliğini artırdığını bildirmişlerdir.

Köklerin yüzey alanının fazla oluşu, bitkilerde köklerin su ve besin maddesi alma kapasitesini artıran bir diğer önemli fenotipik kök özelliğidir. Araştırma sonucunda, kök yüzey alanı yönünden Yedikule marul çeşitleri arasında çok önemli düzeyde farklılıkların $(\mathrm{p}<0.01)$ olduğu tespit edilmiştir. Yedikule marul tipinde en yüksek kök yüzey alanı, kök uzunluğunun da en yüksek olarak belirlendiği YM4 çeşidinde $\left(642.49 \mathrm{~cm}^{2}\right.$ ) kaydedilmiştir. Johnson ve ark. (2020), toprak içerisinde geniş kök dağılımının, yüzeye uygulanan besinlerin verimli kullanımı için avantaj sağladığını bildirerek, yeni çeşitlerde köklerin hem yüzey alanının, hem de kök uzunluğunun fazla olmasının, daha derin ve geniş toprak bölgelerinden yararlanma bakımından gerekli olduğunu belirtmişlerdir.

Çalışmada yer alan marul çeşitlerinde kök hacmi değerleri $6.02-13.50 \mathrm{~cm}^{3}$ arasında dağılış göstermiştir. Yedikule marul çeşitlerinde kök hacmi değerlerinin istatistiksel olarak önemli düzeyde farklılık gösterdiği ( $p<0.01)$ tespit edilmiştir. En yüksek kök hacmi, YM1 $\left(9.86 \mathrm{~cm}^{3}\right)$ çeşidinde kaydedilmiştir. Bu çeşidi YM4 $\left(9.03 \mathrm{~cm}^{3}\right) \mathrm{marul}_{\text {çeşidi }}$ izlemiştir. Li ve ark. (2018), marulda genotipin, kök hacmi özelliği üzerine etkisinin çok önemli olduğunu (p<0.001) ve 45 günlük marul bitkilerinde kök hacminin 1.64-7.24 $\mathrm{cm}^{3}$ arasında değiştiğini tespit etmişlerdir. Araştırma sonuçları ile bu literatür değerleri arasındaki farklılık gün sayısı ve genotip etkisinden ortaya çıkmış olabilir.

Kök uzunluklarının oransal çap sınıf değerleri (\%) bakımından, kıvırcık marul çeşitleri arasında \%5 düzeyinde ve Yedikule marul çeşitleri arasında \%1 düzeyinde istatistiksel olarak önemli düzeyde farklılıklar olduğu belirlenmiştir. Saçak kök yapma eğilimi bakımından kıvırcık marul tipinde \%86.56 değeri ile KM2 çeşidi, Yedikule marul tipinde ise \%92.66 değeri ile YM4 çeşidi ön plana çıkmıştır. Ayrıca Yedikule tipi marul çeşitlerinin saçak kök yapma eğiliminin daha fazla olduğu tespit edilmiştir. Bitkilerin toplam kök uzunlukları içinde çapı 1 mm’den küçük olan köklerin uzunluk oranı saçak kök yapma eğilimini göstermektedir. (Koevoets ve ark. 2016; Suchoff ve ark. 2017; Sarıbaş ve ark. 2019). Saçak kökler, özellikle bitkilerin su ve iyonların alımı için önemlidir (Wulfsohn ve ark. 1999; Koevoets ve ark. 2016). Huang ve Eissentat (2000), 1 mm'den küçük olan köklerin uzunluk oranının fazla oluşunun, su kullanım etkinliğini artırdığını bildirmişlerdir. Pereira-Dias ve ark. (2018), 1 mm'den küçük köklerde besin alımının 1 mm'den büyük köklere göre 4-5 kat daha fazla olduğunu belirtmişlerdir.

\section{SONUÇ VE ÖNERILER}

Marul, toprağın üst katmanlarında kısa bir ana kök ve üretken yan dalları olan yüzlek bir kök sistemine sahiptir. Küçük ve yüzlek kök sistemleri, toprak profilinin alt katmanlarında nem ve besin maddelerine yeterince ulaşamaz. Bu nedenle bitkinin strese girmesini önlemek için sık sık sulama ve gübreleme uygulaması gerekir. Bitkilerde topraktan suyu ve besin maddelerini verimli bir şekilde alabilen kök sistemi mimarileri bu sorunları en aza indirecektir. Bu çalışmadan elde edilen veriler, kıvırcık ve Yedikule marul çeşitlerinin kök sistemi mimarisinin ve kök gelişiminin daha iyi anlaşılmasına yardımcı olacaktır. Kök sistemi mimarisini oluşturan fenotipik kök özelliklerinden toplam kök uzunluğu, ortalama kök çapı, kök yüzey alanı ve kök hacmi değerleri kıvırcık marul çeşitleri arasında farklılık göstermemiş, ancak Yedikule marul çeşitleri arasında önemli düzeyde fark olduğu bulunmuştur. Böylece Yedikule marul çeşitlerinin kök sistemleri arasında kantitatif analizler yardımıyla köklenme gelişimleri arasında morfolojik farklılıkların olduğu ortaya konmuştur. Yedikule marul çeşitlerinden YM4 çeşidi, hem toplam kök uzunluğu, hem yüzey alanı hem de saçak kök yapma eğilimi bakımından diğer Yedikule marul çeşitlerinden daha fazla ön plana çıkmıştır.

Yüksek düzeyde besin ve su kullanımı için iyi karakterize edilmiş kök mimari desenleri elde etmek bakımından, yabani akrabalardan gelen allelleri marul bitkisine aktarmak mümkündür. Gün geçtikçe artan toprak kaynaklı stres faktörlerinin etkisini azaltmak bakımından gelecekte yapılacak çalışmalarda bu ıslah konularına yer verilmesi büyük önem arz etmektedir. Ayrıca gelecekte bitkilerde kök mimarisinin su ve besin maddesi gibi kaynakların kullanımı üzerindeki etkilerine ilişkin çalışmalara yer verilmesi yararlı olacaktır.

\section{ÇIKAR ÇATIŞMASI}

Yazarlar herhangi bir çıkar çatışması bildirmemiştir.

\section{YAZAR KATKISI}

Tüm yazarlar eşit katkı sağlamıştır. 


\section{KAYNAKLAR}

Açıkgöz E 2001.Yem Bitkileri. Uludağ Üniversitesi Güçlendirme Vakfı 182: 584 s.

Ayers RS, Westcot DW 1989. Salinity Problems. Water Quality for Agriculture. FAO, Rome, Italy, s: 1-32.

Balkaya A, Özgen R 2019. Türkiye'de marul yetiştiriciliğinin tarımsal üretimdeki yeri ve ekonomik önemi. Marul Tarımı (Özel Sayı). Tarım Gündem Dergisi ISBN:978-605-7846-39-6.

Bektaş H 2021. The effect of salt stress on root development and architecture in common grasspea (Lathyrus sativus L.) Avrupa Bilim ve Teknoloji Dergisi 23: 793-799.

Bertucci MB, Suchoff DH, Jennings KM, Monks DW, Gunter CC, Schultheis JR, Louw FJ 2018. Comparison of root system morphology of cucurbit rootstocks for use in watermelon grafting. HortTechnology 28: 629-636.

Comas L, Becker S, Cruz VMV, Byrne PF, Dierig DA 2013. Root traits contributing to plant productivity under drought. Frontiers Plant Science 4: 442.

Denli N 2015. Marul Yetiştiriciliği. https://arastirma.tarimorman.gov.tr. (Erişim tarihi: 15 Ağustos, 2021).

Eissenstat DM 1992. Costs and benefits of constructing roots of small diameter. Journal of Plant Nutrition 15(6-7): 763 782.

Eşiyok D 2012. Kışlık ve Yazlık Sebze Yetiştiriciliği. Ege Üniversitesi Ziraat Fakültesi Bahçe Bitkileri Bölümü, İzmir, 404s.

Günay A 2005. Sebze Yetiştiriciliği (Cilt II). Meta Basımevi, İzmir. s: 229-237.

Güvenç İ 2016. Sebzecilik: Temel Bilgiler Muhafaza ve Yetiştiricilik. Kahramanmaraş Sütçü İmam Üniversitesi, Ziraat Fakültesi Bahçe Bitkileri Bölümü, Kahramanmaraş. s: 327-328.

Horuz A, 2019. Gübreleme. Marul Tarımı (Özel Say1). Tarım Gündem Dergisi ISBN:978-605-7846-39-6.

Huang B, Eissenstat DM 2000. Linking hydraulic conductivity to anatomy in plants that vary in specific root length. Journal of the American Society for Horticultural Science 125(2): 260-264.

Jackson LE 1995. Root architecture in cultivated and wild lettuce (Lactuca spp.). Plant, Cell \& Environment 18(8): 885894.

Johnson WC, Jackson LE, Ochoa O, Van Wijk, R Peleman J, Clair DS, Michelmore RW 2000. Lettuce, a shallowrooted crop, and Lactuca serriola, its wild progenitor, differ at QTL determining root architecture and deep soil water exploitation. Theoretical and Applied Genetics 101(7): 1066-1073.

Kanal A, Balkaya A, Karaağaç O 2021. Capsicum baccatum türüne ait biber genotiplerinin fenotipik kök özellikleri yönünden seleksiyonu. Yüzüncü Y1l Üniversitesi Fen Bilimleri Enstitüsü Dergisi 26(1): 19-33.

Kandemir D, Bayındır S 2019. Yetiştirme Tekniği. Marul Tarımı (Özel Sayı). Tarım Gündem Dergisi ISBN:978-6057846-39-6.

Karaağaç O, Balkaya A 2019. Günümüz üretiminde kullanılan çeşit grupları ve özellikleri. Marul Tarımı (Özel Sayı). Tarım Gündem Dergisi ISBN:978-605-7846-39-6.

Karaağaç O, Taş K, Özgen R, Kanal A, Balkaya A 2020. Capsicum türlerinin kök yapılarının incelenmesi ve kök özellikleri yönünden karşılaş̧ırılması. Yüzüncü Yıl Üniversitesi Tarım Bilimleri Dergisi 30(2): 266-279.

Koevoets IT, Venema JH, Elzenga JT, Testerink C 2016. Roots withstanding their environment: exploiting root system architecture responses to abiotic stress to improve crop tolerance. Frontiers in Plant Science 7(1335), 1-19.

Krasilnikoff G, TS Gahoonia, NE Nielsen 2003. Variation in phosphorus uptake efficiency by genotypes of cowpea (Vigna unguiculata) due to differences in root and root hair length and induced rhizosphere processes. Plant and Soil 251: 83-91.

Lambers H, Shane MW, Cramer MD, Pearse SJ, Veneklaas EJ. 2006. Root structure and functioning for efficient acquisition of phosphorus: Matching morphological and physiological traits. Annals of Botany 98: 693-713.

Li Q, Li X, Tang B, Gu M 2018. Growth responses and root characteristics of lettuce grown in aeroponics, hydroponics, and substrate culture. Horticulturae 4(4): 35.

Lopez-Bucio J, Cruz-Ramirez A, Herrera-Estella L 2003. The role of nutrient availability in regulating root architecture. Current Opinion in Plant Biology 6: 280-287.

Lovelli S, Perniola M, Di Tommaso T, Bochicchio R, Amato M 2012. Specific root length and diameter of hydroponically-grown tomato plants under salinity. Journal of Agronomy 11: 101-106.

Murakami T, Yamada K, Yoshid, S 2002. Root distribution of field-grown crisphead lettuce (Lactuca sativa L.) under different fertilizer and mulch treatment. Soil Science and Plant Nutrition 48(3): 347-355.

Murat Doğru Ş, Çilingir A 2019. Toprak ve iklim istekleri. Marul Tarımı (Özel Sayı). Tarım Gündem Dergisi ISBN:978-605-7846-39-6.

Özgür M 2016. Maydanoz ve Salata-Marul Yetiştiriciliği. Ünite 7. Bahçe Tarımı-II. Anadolu Üniversitesi Yayını No: 2358. Açı Öğretim Fakültesi Yayını No:1355.

Paez-Garcia A, Motes CM, Scheible WR, Chen R, Blancaflor EB, Monteros MJ 2015. Root traits and phenotyping strategies for plant improvement. Plants 4: 334-355. 
Kandemir et al. / Manas Journal of Agriculture Veterinary and Life Sciences 11 (2) (2021) 120-130

Pereira-Dias L, Lopez-Serrano L, Castell-Zeising V, Lopez-Galarza S, San Bautista A, Calatayud A, Fita A 2018. Different root morphological responses to phosphorus supplies in grafted pepper. Bulletin UASVM Horticulture 75(1): 59-61.

Sarıbaş Ş, Balkaya A, Kandemir D, Karaağaç O 2019. Yerli patlıcan anaçlarının (Solanum melongena x Solanum aethiopicum) köklenme potansiyeli ve fenotipik kök mimarisi. Black Sea Journal of Agriculture 2(3): $138-146$.

Sarıbaș Ş, Şen Z 2019. Morfolojik Özellikler. Marul Tarımı (Özel Sayı). Tarım Gündem Dergisi ISBN:978-605-784639-6.

Suchoff DH, Gunter CC, Louws FJ. 2017. Comparative analysis of root system morphology in tomato rootstocks. HortTechnology 27(3): 319-324.

Şalk A, Arın L, Deveci M, Polat S 2008. Özel Sebzecilik. Namık Kemal Üniversitesi, Ziraat Fakültesi, Bahçe Bitkileri Bölümü, Tekirdağ, 485s.

Wulfsohn D, Nyengaard JR 1999. Simple stereological procedure to estimate the number and dimensions of root hairs. Plant and Soil 209(1): 129-136 